\title{
The Beginning Solubilization of 20-Methylcholanthrene in Aqueous Solutions of Conjugated and Unconjugated Bile Acid Salts
}

\author{
Bile Acids and Steroids 79
}

\author{
AR NE NORMA N* \\ Department of Physiological Chemistry, University of Lund, Lund, Sweden
}

\begin{abstract}
The first stage of association in aqueous bile salt solutions was studied by measuring the amounts of solubilized 20 -methylcholanthrene. It was otuserved to begin in sodium deoxycholate, chenodeoxycholate and cholate solutions when the concentrations of bile salts rose to approximately $0.005 \mathrm{M}, 0.006 \mathrm{M}$ and $0.012 \mathrm{M}$, respectively. The glycine and taurine conjugates of these bile acid salts were found to undergo initial association in approximately the same concentration ranges as the respective unconjugated bile salts. The sodium and potassium salts of lithocholic and cholanic acids and their taurine and glycine conjugates were found to be only sparingly soluble in water. Even seturated solutions of these compounds were unable to solubilize 20-methylcholanthrene.
\end{abstract}

Studies carried out using various colloid-chemical methods have shown clearly that association to micelles takes place in aqueous solutions of the sodium salts of conjugated and unconjugated bile acids. The previous work in this field has been reviewed by Ekwall et al. ${ }^{1,2}$.

The ability to solubilize lipoid substances is a characteristic property of association colloids and the establishment of a beginning solubilization can be taken to indicate the occurrence of association. Ekwall ${ }^{3}$ introduced the use of fluorescent polycyclic hydrocarbons in the study of the solubilizing power of association colloids and in the determination of the colloid concentration where solubilization begins. The solubilities of these hydrocarbons can be readily determined by measuring the fluorescence or ultraviolet absorption of their solutions.

* Present address: Department of Chemistry, Karolinska Institutet, Stockholm 60, Sweden. 


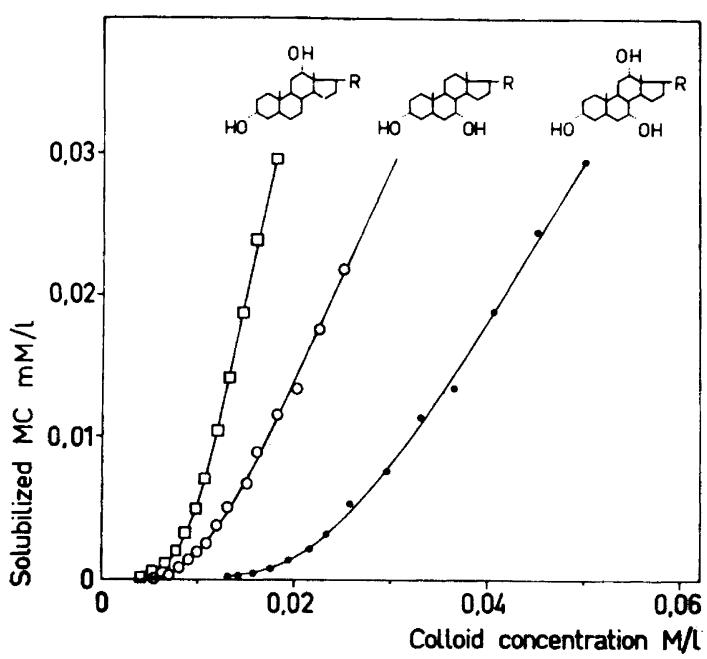

Fig. 1. Solubilization of 20-methylcholanthrene in aqueous solutions of sodium deoxycholate $(\square-\square)$, sodium chenodeoxycholate $(O-O)$, and sodium cholate $(0-0)$.

The aim of the present study was to compare the first stages of association in solutions of bile acid salts and their taurine and glycine conjugates. The present paper reports the results of fluorometric determinations of the beginning solubilization of 20 -methylcholanthrene in solutions of sodium cholate, deoxycholate, chenodeoxycholate, lithocholate and cholanate and their taurine and glycine conjugates.

\section{MATERIALS AND METHODS}

20-Methylcholanthrene (MC) was a product of Eastman-Kodak Co., Rochester, N.Y.

The synthesis and physical properties of the conjugated and unconjugated bile acid salts were reported in a previous paper of the author 4.

Methylcholanthrene was added in excess to ampoules containing the bile salt solutions. After they had been closed by fusion, the ampoules were shaken at $40^{\circ} \mathrm{C}$ for $48 \mathrm{~h}$. After this period the undissolved methylcholanthrene was removed from the solutions by filtration and the amounts of methylcholanthrene solubilized by the solutions were determined by measuring the intensity of fluorescence (according to Ekwall et al. ${ }^{5}$ ) or the ultraviolet absorption (according to Klevens ${ }^{6}$ ). The fluorescence intensities were measured with a Beckman Model DU Quartz Spectrophotometer provided with the fluorescence accessory

Table 1.

Bile acid salt

Potassium taurolithocholate Potassium glycolithocholate Potassium glycocholanate Potassium taurocholanate

\begin{tabular}{lc}
\multicolumn{2}{c}{ Solubility } \\
mole/litre \\
$20^{\circ}$ & $40^{\circ}$ \\
0.001 & 0.0025 \\
0.0004 & 0.0007 \\
0.0006 & 0.001 \\
& 0.001
\end{tabular}

Acta Chem. Scand. 14 (1960) No. 6 


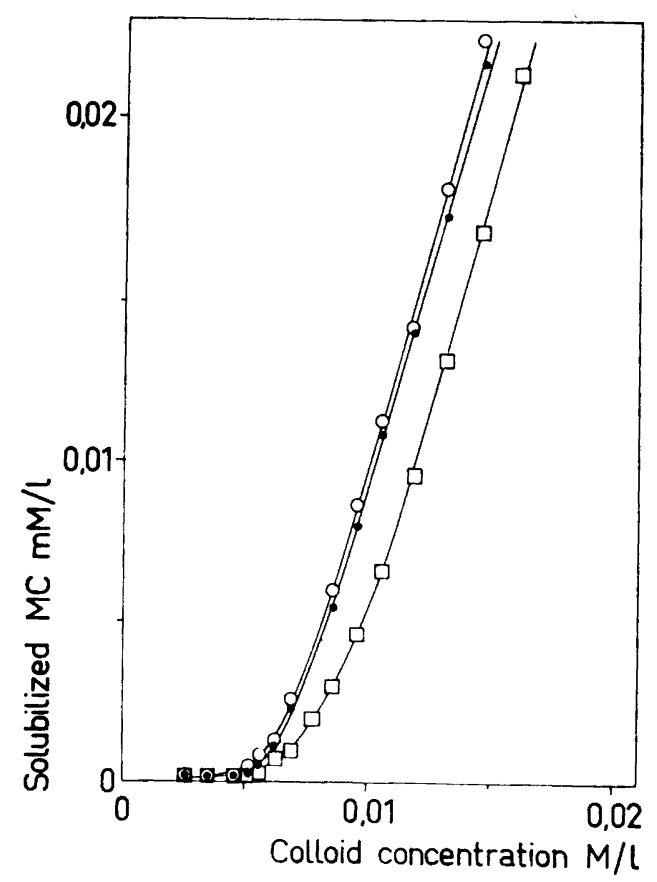

Fig. 2. Solubilization of 20-methylcholanthrene in aqueous solutions of sodium deoxycholate, $(\square-\square)$ sodium taurodeoxycholate $(\mathrm{O}-\mathrm{O})$, and sodium glycodeoxy. cholate $(\mathrm{O}-\mathrm{O})$.

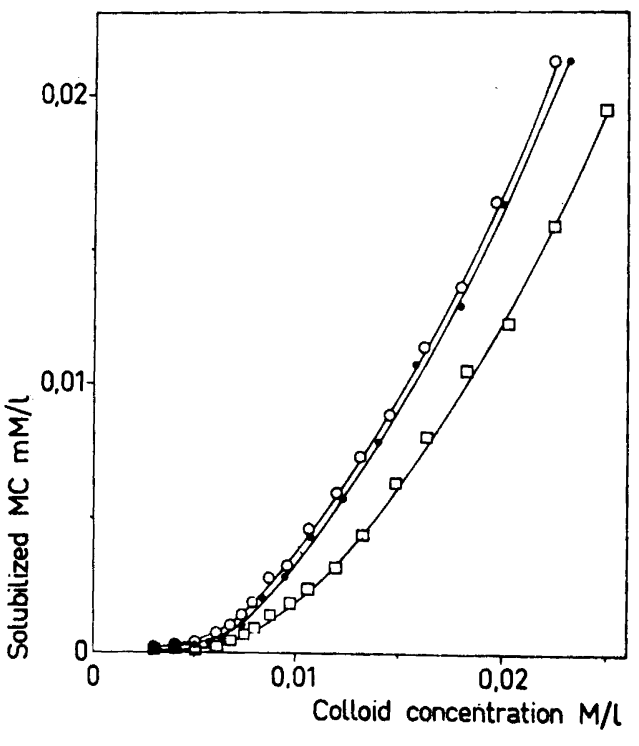

Fig. 3. Solubilization of 20-methylcholanthrene in aqueous solutions of sodium chenodeoxycholate $(\square-\square)$, sodium taurochenodeoxycholate $(\mathrm{O}-\mathrm{O})$, and sodium glycochenodeoxycholate (O-O).

set. The measurements were all made at room temperature. No precipitation was found to occur when the temperature decreased from $40^{\circ}$ to $20^{\circ} \mathrm{C}$, which is in accordance with the observation of Sjöblom ${ }^{7}$ that the solubilizing power of bile acid salts does not diminish with decreasing temperature.

Reference solutions containing different amounts of methylcholanthrene in the same bile salt solution were prepared as follows. A known volume of a standard solution of methylcholanthrene in benzene was added from an Agla micrometer burette to an ampoule and the benzene was evaporated from the ampoule in vacuo at room temperature. A measured volume of the bile salt solution was introduced into the ampoule which, after it was closed by fusion, was shaken in a thermostat at $40^{\circ}$ for $48 \mathrm{~h}$.

\section{RESULTS}

The time necessary to attain maximal solubility of methyloholanthrene in the solutions was studied by determining the amounts of methylcholanthrene solubilized after the ampoules were shaken for different lenghts of time at $40^{\circ} \mathrm{C}$. The results obtained with $0.04 \mathrm{M}$ cholate and $0.015 \mathrm{M}$ deoxycholate solutions revealed that equilibrium was attained after $24 \mathrm{~h}$. 


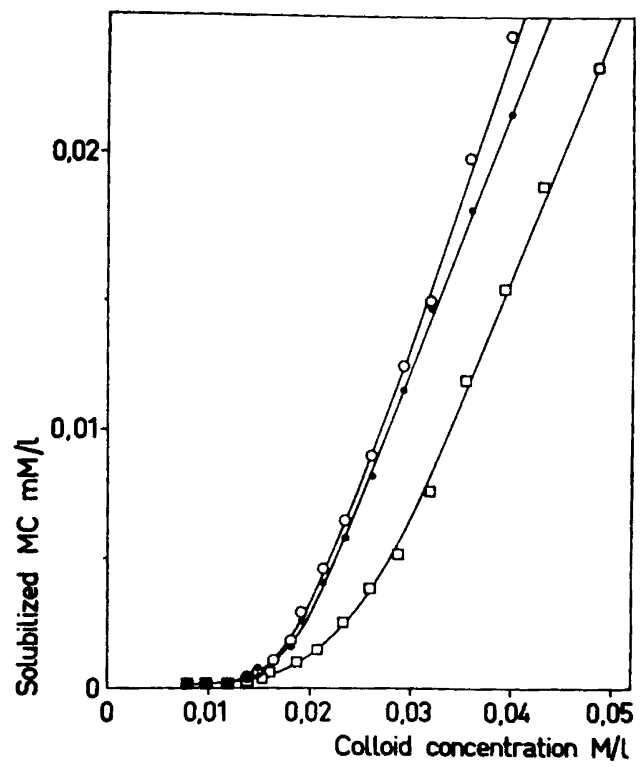

Fig. 4. Solubilization of 20-methylcholanthrene in aqueous solutions of sodium cholate $(\square-\square)$, sodium taurocholate $(\mathrm{O}-\mathrm{O})$, and sodiumglycocholate $(0-0)$.

In a number of cases the amounts of solubilized methylcholanthrene were determined by both fluorescence and ultraviolet absorption methods. Conforming results were obtained by both methods. However, the fluorescence method is appreciably more sensitive and is hence more suitable for the determination of the low solubility when a low degree of association prevails in the colloid solution.

Figs. 1-4 show the results of solubilization determinations by the fluorescence method on solutions of the sodium salts of deoxycholic, chenodeoxycholic and cholic acids and their taurine and glycine conjugates. All these compounds are very soluble in water and the beginning solubilization becomes clearly evident within a narrow concentration range in their solutions. Similar experiments were carried out on solutions of the sodium and potassium salts of lithocholic and cholanic acids and their taurine and glycine conjugates but no solubilization of methylcholanthrene was observed to take place even in their saturated solutions. These compounds are, however, only sparingly soluble in water as shown by the solubilities of the potassium salts of the conjugated acids at $20^{\circ}$ and $40^{\circ}$ (Table 1). The solubilities of the sodium and potassium salts are approximately equal and the salts of lithocholic and cholanic acids are less soluble than the corresponding salts of the conjugated acids.

\section{DISCUSSION}

By determining the solubilities of $p$-xylene, cholio acid, cholesterol and 20-methylcholanthrene in cholate solutions, Ekwall and his collaborators 1,2 found that a beginning solubilization occurs when the cholate concentration 
rises to about $0.015 \mathrm{M}$. The activity of the cholate anion in cholate solutions saturated with cholic acid also changes at the same concentration owing to the beginning association. The corresponding data for sodium deoxycholate show that the first signs of association are observed at a concentration of about $0.005 \mathrm{M}$. These experiments reveal that the number of hydroxyl groups and their location in the molecule influence the association process. The curves in Fig. 1 show that the solubilizing powers of chenodeoxycholate solutions are weaker than those of deoxycholate solutions. In addition, solubilization begins at a somewhat higher concentration in chenodeoxycholate solutions than in deoxycholate solutions. Hydroxyl groups at carbon atoms 3 and 12 (deoxycholic acid) favour micellar association more than hydroxyl groups at carbon atoms 3 and 7 (chenodeoxycholic acid).

The configurations of the side chains in bile salts apparently have a lesser influence on the association process and the properties of the micelles than the structure of the ring skeleton. Figs. 2, 3 and 4 show that the concentration where beginning association occurs do not differ essentially for the conjugated and unconjugated bile salts with the possible exception that the solubilization begins at a slightly lower concentration in the case of the conjugated salts. The solubilizing powers of the taurine and glycine conjugates are practically equal and slightly greater than those of the corresponding unconjugated bile salts. The solubilizing powers increase more rapidly and become linear, i.e., the ratio of the amount of hydrocarbon solubilized and the concentration of the association colloid becomes constant, at lower concentrations of the conjugated salts.

Acknowledgement. This investigation was begun at the Institute of Physical Chemistry, Åbo Akademi. I wish to express my gratitude to Professor Per Ekwall, the Head of the Institute, for his guidance.

This work has been supported by grants awarded by the Medical Faculty, University of Lund, Statens Medicinska Forskningsråd, Stockholm and the National Heart Institute (H2842), U.S. Public Health Service, Bethesda, Maryland.

\section{REFERENCES}

1. Ekwall, P., Fontell, K. and Sten, A. Proc. 2nd Intern. Congr. Surface Activity, Gas| Liquid and Liquid/Liquid Interface, Butterworths, London 1957, p. 357.

2. Ekwall, P. and Ekholm, R. Proc. 2nd Intern. Congr. Surface Activity, Gas/Liquid and Liquid/Liquid Interface, Butterworths, London 1957, p. 23.

3. Ekwall, P. Nord. Kemistmötet. Berättelse och Föredrag. 6th Meeting, Lund 1947, p. 179.

4. Norman, A. Arkiv. Kemi 8 (1955) 331.

5. Ekwall, P., Setälä, K. and Sjöblom, L. Acta Chem. Scand. 5 (1951) 175.

6. Klevens, H. B. J. Phys. \& Colloid. Chem. 54 (1950) 283.

7. Sjöblom, L. Acta Acad. Aboensis, Math. et Phys. XXI (1958) No. 6.

8. Sjöblom, L. Acta Acad. Aboensis, Math. et Phys. XX (1956) No. 14.

Received March 1, 1960.

Acta Chem. Scand. 14 (1960) No. 6 